\title{
Comparison of In Chemico Skin Sensitization Methods and Development of In Chemico Skin Photosensitization Assays
}

\author{
Nitin H. Patel, Priyanka K. Mishra, Rajendra Nagane, Abhay Deshpande, Irfan Y. Tamboli and Rahul Date
}

Research \& Development Division, Jai Research Foundation, Valvada, Gujarat, India

\begin{abstract}
Chemical substances that induce an allergic response in skin upon contact are called skin allergens or sensitizers, while chemical substances that elicit an allergic response only in the presence of light are called photoallergens or photo sensitizers. The Direct Peptide Reactivity Assay (DPRA, OECD TG 442C, 2015) and the Amino Acid Derivative Reactivity Assay (ADRA) are in chemico assays used to discriminate between allergens and non-allergens. The DPRA and the ADRA respectively monitor the depletion of model peptides and modified amino acids induced by crosslinking with test chemicals. In the current study, we compared these two assays and analyzed their suitability to predict the skin sensitization potential of several chemical substances. In order to study the combined effect of a chemical compound and UV light, we modified the DPRA (photo-DPRA) as well as the ADRA (photo-ADRA) by introduction of a photo-irradiation parameter. Analysis using photo-DPRA and photo-ADRA correctly distinguished known photoallergens from non-photoallergens. Upon irradiation, photoallergens selectively showed higher depletion of model peptides or modified amino acids. Thus, photo-DPRA and/or photo-ADRA can serve as non-animal in vitro methods for the identification and assessment of photoallergens/photosensitizers.
\end{abstract}

\section{Introduction}

Allergic contact dermatitis (ACD) induced by repeated skin exposure of low molecular weight chemicals is characterized by skin rash, itch, and other complications such as erythema and edema. Chronic exposure may lead to skin thickening and eczema with cracks from itching. Exposure to allergens causes T-cell activation and proliferation that triggers adverse effects resulting in the dermal symptoms of ACD (Silvestre et al., 2018). Skin allergens can be identified using epidemiological data, clinical case studies, and sensitization/allergy tests (patch or maximization test) in humans (Basketter and Safford, 2016). Traditionally, animal based in vivo methods such as the mouse Local Lymph Node Assay (LLNA) and the guinea pig maximization test were used for the same purpose (Kimber et al., 2001). However, regulatory requirements borne out of ethical considerations are now driving the development of non-animal alternative tests.

Regulatory bodies across the globe, including the European Union Reference Laboratory for Alternatives to Animal Testing (EURL ECVAM) and the Food and Drug Administration (FDA,
US), recommend multiple integrated testing strategies (ITS) using non-animal test batteries that combine in silico, in chemico, and in vitro methods to identify skin allergens (EURL ECVAM, 2013; Strickland et al., 2017; Daniel et al., 2018; Roberts and Patlewicz, 2018; Prior et al., 2019). ITS suggested for skin allergy prediction propose assessment of test chemicals using multiple OECD adopted non-animal in vitro methods such as the Direct Peptide Reactivity Assay (DPRA) (OECD, 2015), KeratinoSens $^{\mathrm{TM}}$ (OECD, 2018a), and human Cell Line Activation Test (h-CLAT) (OECD, 2018b) (Hoffmann et al., 2018). These three test methods are based on the adverse outcome pathway (AOP), described by OECD, which defines the molecular initiating event (MIE) as well as the key events (KEs) that link the sequence of causal incidences with the manifestation of adverse health or environmental effects (Sewell et al., 2018). The skin allergenic response begins with the formation of covalent adducts between the chemical allergen and endogenous proteins, which constitutes the MIE, or KE1, followed by a keratinocyte inflammatory response (KE2), activation of dendritic cells (KE3), and T-cell proliferation in lymph nodes (KE4) (OECD, 2014; Schultz et al., 2016).
Received November 1, 2018; Accepted March 11, 2019; Epub March 11, 2019; (C) The Authors, 2019.

ALTEX 36(3), 373-387. doi:10.14573/altex.1811011

Correspondence: Irfan Y. Tamboli, PhD, Rahul Date, PhD

R \& D Division, Jai Research Foundation, Near Daman Ganga Bridge,

$\mathrm{NH}-48$, Valvada, Gujarat - 396105, India

(irfan.tamboli@jrfonline.com), (rahul.date@jrfonline.com)
This is an Open Access article distributed under the terms of the Creative Commons Attribution 4.0 International license (http://creativecommons.org/licenses/by/4.0/), which permits unrestricted use, distribution and reproduction in any medium, provided the original work is appropriately cited. 
The DPRA (OECD TG 442C) (OECD, 2015) and ADRA (Fujita et al., 2014; Gerberick, 2016) are in chemico assays that are designed to investigate the MIE and distinguish between allergens and non-allergens by measuring the extent of covalent crosslinking of test chemicals with model peptides or modified amino acids, respectively. The DPRA is a simple, versatile, and widely used assay that evaluates the reactivity of a test chemical with synthetic heptapeptides containing either cysteine (Cys-peptide) or lysine (Lys-peptide), whereas the ADRA evaluates the crosslinking of test chemicals with novel cysteine derivative N-(2-(1-naphthyl) acetyl)-1-cysteine (NAC) and novel lysine derivative $\alpha-\mathrm{N}-(2-(1-n a p h t h y l)$ acetyl)-1-lysine (NAL). Both DPRA and ADRA analyze peptide reactivity indirectly by determining percent (\%) depletion of model heptapeptides or NAC and NAL, respectively. For the DPRA, a threshold of $6.38 \%$ average for Cys- and Lys-peptide depletion is used to discriminate between allergens and non-allergens, while for Cys-peptide alone this threshold is $13.89 \%$ (OECD, 2015). The suggested average \% NAC and NAL depletion threshold value for ADRA is $7.75 \%$. Thus, model peptides or NAC and NAL depletion data can be used to study the skin allergy hazard classification of a test substance and identify whether or not it is an allergen (Fujita et al., 2014). The data presented herein validate the utility of the DPRA to predict the nature of low molecular weight chemical compounds as per OECD TG 442C. The ADRA prediction closely matches that of the DPRA.

Most chemical allergens contain an electrophilic group that allows direct covalent binding with skin proteins to form immunogenic protein-hapten adducts. A significant number of sensitizers without electrophilic moieties require biotic (mediated by interaction with skin enzymes) or abiotic (mediated by interaction with air/water oxygen, radiation) transformation and are accordingly termed pro-haptens or pre-haptens, respectively (Urbisch et al., 2016). Chemical substances and drugs, such as tetracycline, piroxicam, chlorpromazine (CPZ), amiodarone, and naproxen are pre-haptens that do not show intrinsic peptide reactivity and act as sensitizers only in combination with light (Drucker and Rosen, 2011). Topical and systemic exposure of such drugs, cosmetics, or other environmental chemicals in the presence of UV light can induce cutaneous manifestations such as sunburn dermatitis, planus lichenoids, etc. (Sharma et al., 2013), which can be phototoxic and/or photoallergic (photosensitizing) in nature (Glatz and Hofbauer, 2012). Phototoxic reactions induce direct tissue damage due to reactive oxygen species, whereas photoallergic reactions induced by photosensitizers/ photoallergens resemble ACD. Here, we present data from the modified DPRA (photo-DPRA) and ADRA (photo-ADRA) that supports the application of these in chemico assays in the prediction of photoallergy induced by test chemicals.

\section{Materials and methods}

\section{Chemicals and reagents}

Hepta-peptides containing cysteine (Ac-RFAACAA-COOH) or lysine (Ac-RFAAKAA-COOH) were obtained from RS Synthesis (Louisville, KY, USA). Purity of both peptides was above
95\%. NAC and NAL were custom-synthesized and purchased from GRK Research Laboratories Pvt Ltd, Hyderabad, India. Purity of NAC and NAL was confirmed using 1H NMR (data not shown). Table 1 contains the list of chemicals used in the study and their suppliers. All other chemicals and solvents were obtained from Sigma.

\section{DPRA}

DPRA was performed as per OECD TG $442 \mathrm{C}$ guidelines. Briefly, cysteine and lysine peptide stock solutions were prepared at $0.667 \mathrm{mM}$ final concentration in $100 \mathrm{mM}$ phosphate buffer $(\mathrm{pH} 7.5)$ and ammonium acetate buffer $(\mathrm{pH}$ 10.2), respectively. $100 \mathrm{mM}$ stock solutions of test chemicals were prepared in acetonitrile or in the indicated solvent (Tab. 1). All samples were prepared in triplicate. $750 \mu \mathrm{l}$ Cys-peptide was mixed with 200 $\mu \mathrm{l}$ acetonitrile and $50 \mu \mathrm{l}$ test chemical, i.e., $0.5 \mathrm{mM}$ peptide and $5 \mathrm{mM}$ of the test chemical (1:10 $\mathrm{mM}$ ratio). The Lys-peptide reaction contained $750 \mu \mathrm{l}$ Lys-peptide from stock solution and $250 \mu \mathrm{l}$ of test chemical, i.e., $0.5 \mathrm{mM}$ of the peptide and $25 \mathrm{mM}$ of the test chemical (1:50 mM ratio). Peptides at $0.0167,0.0334,0.0668$, $0.1335,0.2670$, and $0.534 \mathrm{mM}$ were used to generate a standard calibration curve. Reaction vials were incubated in the dark at $25^{\circ} \mathrm{C}$ for $24 \pm 2 \mathrm{~h}$. Next, samples were analyzed by reverse-phase HPLC (Agilent technology 1100 series: Chemstation, Shimadzu LC2010CHT: LC solutions) with UV detection at wavelength $220 \mathrm{~nm}$ using Zorbax SB-C-18 $2.1 \mathrm{~mm} \times 100 \mathrm{~mm} \times 3.5$-micron column and $\mathrm{C} 18$ guard cartridge $(2.0 \times 4.0 \mathrm{~nm})$. The system was equilibrated at $30^{\circ} \mathrm{C}$ with $50 \%$ mobile phase $\mathrm{A}(0.1 \%(\mathrm{v} / \mathrm{v})$ trifluoroacetic acid in water) and $50 \%$ phase B $(0.085 \%(\mathrm{v} / \mathrm{v})$ trifluoroacetic acid in acetonitrile) for at least $2 \mathrm{~h}$ before running samples. $5 \mu \mathrm{l}$ sample was injected and separation was achieved using a $0.35 \mathrm{ml} / \mathrm{min}$ flow rate with a gradient of mobile phase over a 20 min period. The gradient was adjusted from $90 \% \mathrm{~A} / 10 \% \mathrm{~B}$ to $10 \% \mathrm{~A} / 90 \% \mathrm{~B}$ during the initial $13 \mathrm{~min}$. The gradient was then rapidly returned to $90 \% \mathrm{~A} / 10 \% \mathrm{~B}$ over $30 \mathrm{~min}$. The concentration of peptide was determined in each reaction by measuring absorbance at $220 \mathrm{~nm}$. The appropriate peak was integrated, yielding the peak area corresponding to the individual unreacted peptide in the test reactions, controls, and standards. A linear calibration curve was prepared based on the peptide concentration standards. The calibration curve was generated by plotting peak area vs peptide concentration. The calibration curve was considered valid if the correlation coefficient $\left(\mathrm{r}^{2}\right)$ was $>0.990$.

\section{ADRA}

The ADRA was carried out according to methods described by Fujita et al. (2014). Briefly, $1.25 \mathrm{mM}$ NAC was dissolved in $100 \mathrm{mM}$ phosphate buffer (pH 9.5) and $1.25 \mathrm{mM}$ NAL was dissolved in $100 \mathrm{mM}$ phosphate buffer ( $\mathrm{pH}$ 12.0). Test chemical stock solutions were prepared in acetonitrile/water at $100 \mathrm{mM}$. Stock solutions of amino acid derivatives, test chemicals, acetonitrile, and phosphate buffer were mixed, and $80 \mu 1 \mathrm{NAC} / \mathrm{NAL}$ stock solution, $70 \mu \mathrm{l}$ buffer, $40 \mu 1$ acetonitrile, and $10 \mu 1$ (for NAC) or $50 \mu \mathrm{l}$ (for NAL) test chemicals were mixed and incubated in the dark for $24 \pm 2 \mathrm{~h}$ at $25^{\circ} \mathrm{C}$. Post incubation, samples were diluted 10 times with a solution of $25 \%$ acetonitrile and $0.5 \%$ trifluoroacetic acid (TFA) in water. $10 \mu \mathrm{l}$ of NAC and NAL 
Tab 1: Commercial sources, CAS No, and solvents used for dissolving the test chemicals EGDMA, ethylene glycol dimethacrylate; DNCB, 2,4-dinitrochlorobenzene

\begin{tabular}{|c|c|c|c|c|}
\hline Sr. No. & Test chemicals & Source & CAS No. & Soluble in \\
\hline 1 & DNCB & Sigma & $97-00-7$ & Acetonitrile \\
\hline 2 & Oxazolone & Sigma & $15646-46-5$ & Acetonitrile \\
\hline 3 & Formaldehyde & Sigma & $50-00-0$ & Acetonitrile \\
\hline 4 & Benzylideneacetone & Sigma & $122-57-6$ & Acetonitrile \\
\hline 5 & Farnesal & Sigma & $19317-11-4$ & Acetonitrile \\
\hline 6 & 2,3-Butanedione & Sigma & $431-03-8$ & Acetonitrile \\
\hline 7 & 1-Butanol & Sigma & $71-36-3$ & Acetonitrile \\
\hline 8 & 6-Methylcoumarin & Sigma & $92-48-8$ & Acetonitrile \\
\hline 9 & Lactic acid & Flurochem Ltd. & $50-21-5$ & Acetonitrile \\
\hline 10 & 4-Methoxyacetophenone & Sigma & $100-06-1$ & Acetonitrile \\
\hline 12 & Cinnamyl alcohol & Sigma & $104-54-1$ & Acetonitrile \\
\hline 13 & EGDMA & Sigma & $150-38-9$ & Acetonitrile \\
\hline 14 & 2-Mercaptobenzothiazole & Sigma & $149-30-4$ & Acetonitrile \\
\hline 15 & 4-Methoxyamino hemisulfate & Sigma & $55-55-0$ & Water \\
\hline 16 & 2-Propanol & Sigma & $67-63-0$ & Acetonitrile \\
\hline 17 & Salicylic acid & Sigma & $69-72-7$ & Acetonitrile \\
\hline 18 & Glycerol & Sigma & $56-81-5$ & Water \\
\hline 19 & Chloramine-T & Sigma & $7080-50-4$ & Water \\
\hline 20 & Phenylacetaldehyde & Sigma & $122-78-1$ & Acetonitrile \\
\hline 21 & Vanillin & Sigma & $121-33-5$ & Acetonitrile \\
\hline 22 & Imidazolidinyl urea & Sigma & $39236-46-9$ & Water \\
\hline 23 & Guaiacol & Sigma & $90-05-1$ & Acetonitrile \\
\hline 24 & Phenol & Sigma & $108-95-2$ & Acetonitrile \\
\hline 25 & Ethanolamine & Sigma & $141-43-5$ & Acetonitrile \\
\hline 26 & Furaltadone & Sigma & $139-91-3$ & Acetonitrile \\
\hline 27 & Propylene glycol & Sigma & $57-55-6$ & Acetonitrile \\
\hline 28 & Glutaraldehyde & Sigma & $111-30-8$ & Acetonitrile \\
\hline 29 & Amiodarone $\mathrm{HCL}$ & Sigma & $19774-82.4$ & Acetonitrile:water \\
\hline 30 & Chlorpromazine HCL & Sigma & $69-09-0$ & Acetonitrile \\
\hline 31 & Anthracene & Sigma & $120-12-7$ & Acetone \\
\hline 32 & Protoporphyrin IX, disodium & Sigma & $50865-01-5$ & Acetonitrile \\
\hline 33 & L-Histidine & Sigma & $5934-29-2$ & Water \\
\hline 34 & Hexachlorophene & MP Biomedicals & $70-30-4$ & DMSO \\
\hline 35 & Sodium lauryl sulfate & Sigma & $151-21-3$ & Water \\
\hline 36 & Norfloxacin & Sigma & $70458-96-7$ & Ammonium acetate buffer, $\mathrm{pH} 10.2$ \\
\hline
\end{tabular}

samples were injected and their levels were quantified using HPLC-UV (HPLC-Agilent technology 1100 series, Shimadzu LC2010CHT) at a wavelength of $281 \mathrm{~nm}$. Zorbax SB-C-18 $2.1 \mathrm{~mm} \times 100 \mathrm{~mm} \times 3.5$ micron column and C18 guard cartridge $(2.0 \times 4.0 \mathrm{~nm})$ were used.

The mobile phase had a flow rate of $0.3 \mathrm{ml} / \mathrm{min}$; it consisted of A (98:02 mixture of water:acetonitrile with $0.1 \%$ trifluoroacetic acid) and B (90:10 mixture of acetonitrile:water with $0.1 \%$ trifluoroacetic acid). Separation was achieved by holding the initial condition $(20 \% \mathrm{~B})$ for $7 \mathrm{~min}$, followed by a linear gradient to $100 \% \mathrm{~B}$ for $3.5 \mathrm{~min}$, and then back to the initial condition over a total analysis time of 20 min per sample. Mobile phase conditions were altered for test chemicals that co-eluted with NAL:phenylacetaldehyde and guaiacol (gradient starting linearly at $20 \%$ B for $2 \mathrm{~min}$ to $50 \%$ B until $12 \mathrm{~min}$, to $100 \%$ B until $12.5 \mathrm{~min}$, linear $100 \%$ B until $15 \mathrm{~min}$, linear $35 \%$ B until $20 \mathrm{~min}$, flow rate $0.3 \mathrm{ml} / \mathrm{min}$ ), and oxazolone and 2-mercaptobenzothiazole (gradient starting at $45 \% \mathrm{~B}$ to $55 \%$ B over $10 \mathrm{~min}$, followed by $100 \%$ B from $10.5 \mathrm{~min}$ to $13.5 \mathrm{~min}$, to $45 \%$ B linearly from $13.5 \mathrm{~min}$ to $20 \mathrm{~min}$, flow rate $0.2 \mathrm{ml} / \mathrm{min}$, run time $20 \mathrm{~min}$ ). Mobile phase conditions were altered for 6-methylcoumarin, which co-eluted with NAC (gradient starting at 35\% B linearly 
for $2 \mathrm{~min}$, followed by $35 \% \mathrm{~B}$ to $60 \% \mathrm{~B}$ until $12 \mathrm{~min}$, to $100 \% \mathrm{~B}$ until $12.5 \mathrm{~min}$, linearly to $100 \% \mathrm{~B}$ until $15 \mathrm{~min}$, linearly to $35 \%$ B until $20 \mathrm{~min}$, flow rate $0.3 \mathrm{ml} / \mathrm{min}$ ).

\section{Photo-DPRA and photo-ADRA}

All chemicals were prepared as $100 \mathrm{mM}$ stock solutions except anthracene and norfloxacin. Due to their lower solubility, these were prepared as $50 \mathrm{mM}$ and $33.33 \mathrm{mM}$ stock solutions, respectively. Accordingly, the final concentration of these compounds in the assay was lower compared to the other chemicals. Most parameters used for DPRA and ADRA were transferred to the photo-DPRA and photo-ADRA. Test chemicals were mixed with model peptides or NAC/NAL and the mixture was exposed to UVA.

The UV cabinet was sourced from Scientific Sales Syndicate (N P Botny model); it was equipped with UVA (365 nm), UVB (254 nm), and visible light lamps. A handheld digital UV meter from Sai Water Equipment, which utilizes a stable photovoltaic sensor with a UV pass filter that blocks visible and infrared radiation, was used to measure the light intensity before each experiment. The exposure time was adjusted to achieve a dose of $5 \mathrm{~J} / \mathrm{cm}^{2}$. Reaction vials were incubated in the dark at $25^{\circ} \mathrm{C}$ for $24 \pm 2 \mathrm{~h}$ and HPLC analysis was performed as described above in the DPRA and ADRA methods.

\section{Statistics}

Each experiment was repeated at least three times. Mean \% depletion values of heptapeptides and modified amino acids from three or more independent experiments are shown in the Results section. Standard deviation (SD) and relative coefficient of variability (RCV) values were calculated and are indicated in the respective tables. SD and RCV values are useful in determining the data accuracy and reproducibility. Generation of DPRA and ADRA calibration curves is described in supplementary data S2 and $\mathrm{S}^{1}$, respectively. As per the DPRA acceptance criteria (described briefly below) mentioned in the OECD guidelines, interpretation of the results must be based on the $\mathrm{r}^{2}$ (square of the coefficient of correlation) value obtained from standard calibration curves of Cys- and Lys-peptides as well as SD and RCV values of reference controls, positive control, and test chemicals. If these criteria were not met, the data were rejected and the run was repeated. Note that an $r^{2}$ value close to unity indicates the linear correlation between UV absorbance and varying concentrations of Cys/Lys-peptide and NAC/NAL, in DPRA and ADRA, respectively.

\section{DPRA acceptance criteria}

The following criteria had to be met for a run to be considered valid: a) The standard calibration curve should have an $\mathrm{r}^{2}>0.99$. b) The mean percent peptide depletion value of the three replicates for the positive control cinnamaldehyde should be between $60.8 \%$ and $100 \%$ for the cysteine peptide and between $40.2 \%$ and $69.0 \%$ for the lysine peptide; the maximum SD for the positive control replicates should be $<14.9 \%$ for the percent cysteine depletion and $<11.6 \%$ for the percent lysine depletion. c) The mean peptide concentration of reference control A should be $0.50 \pm 0.05 \mathrm{mM}$ and the RCV of peptide peak areas for the nine reference controls $\mathrm{B}$ and $\mathrm{C}$ in acetonitrile should be $<15.0 \%$.

The following criteria should be met for a test chemical's results to be considered valid: a) The maximum SD for the test chemical replicates should be $<14.9 \%$ for the percent cysteine depletion and $11.6 \%$ for the percent lysine depletion. b) The mean peptide concentration of three reference controls $\mathrm{C}$ in the appropriate solvent should be $0.50 \pm 0.05 \mathrm{mM}$. Some batches of acetonitrile have a negative impact on Cys-peptide stability. As per guidelines, acetonitrile batches that show $<15 \% \mathrm{RCV}$ in the Cys-peptide stability should be used.

\section{Results}

\subsection{Fulfillment of DPRA acceptance criteria as per OECD TG 442C}

Synthetic Cys- and Lys-peptides with purities of $98.2 \%$ and $98.4 \%$, respectively, were obtained and stock solutions of 0.667 $\mathrm{mM}$ were prepared for both peptides. Their detection as well as separation methods were established using HPLC-UV, as described in OECD TG 442C (OECD, 2015).

As recommended by EURL ECVAM guidelines, we assessed the influence of the mobile phase component acetonitrile on the stability of the Cys-peptide (Tab. S1 ${ }^{1}$ ) at $25^{\circ} \mathrm{C}$ for $48 \mathrm{~h}$ (EURL ECVAM, 2013). Additionally, the stability of the Lys-peptide $\left(\mathrm{Tab} . \mathrm{S}_{\mathrm{B}} \mathrm{B}^{1}\right)$ in acetonitrile for $24 \mathrm{~h}$ was also checked. The concentration of Cys-peptide at $0 \mathrm{~h}, 24 \mathrm{~h}, 48 \mathrm{~h}$ and of Lys-peptide at $0 \mathrm{~h}$ and $24 \mathrm{~h}$ was determined by using calibration curve data (Fig. S2B, S2C; Tab. S2D ${ }^{1}$ ). Note that the concentration of both Cys- and Lys-peptides at each time point is within the OECD prescribed limits of $0.50 \pm 0.05 \mathrm{mM}$, indicating their stability.

Cys- and Lys-peptide standards were prepared as described (Tab. S2A ${ }^{1}$ ) and calibration curves for both peptides were generated using concentrations from $0.534 \mathrm{mM}$ to $0.0167 \mathrm{mM}$ (Fig. S2B, S2 $\mathrm{C}^{1}$ ). Both peptides showed a linear correlation between dose and UV absorption at $220 \mathrm{~nm}\left(\mathrm{r}^{2} \geq 0.99\right)$. $\mathrm{R}^{2}$ values for four different calibration experiments are shown in Tab. $\mathrm{S}^{2} \mathrm{D}^{1}$. $\mathrm{R}^{2} \geq 0.99$ fulfils the first OECD acceptance criterion. Next, as per guidelines, we also met the second major acceptance criterion for the positive control cinnamaldehyde (Fig. 1). Figure 1 shows the representative chromatograms of reference control B obtained from the Cys-peptide (Fig. 1A) and Lys-peptide (Fig. 1C) in acetonitrile solvent after $24 \mathrm{~h}$ incubation, as well as of the samples containing Cys-peptide (Fig. 1D) and Lys-peptide (Fig. 1D) after $24 \mathrm{~h}$ incubation with cinnamaldehyde. Mean \% depletion values for Cys- and Lys-peptides were determined by comparing AUC (area under curve) of sample (cinnamaldehyde) and of reference control B according to Formula 1:

Percent Peptide Depletion $=\left[1-\left(\frac{\text { Peptide peak area in replicate injection }}{\text { Mean peptide area in reference controls C }}\right)\right] \times 100$

1 doi:10.14573/altex.1811011s 


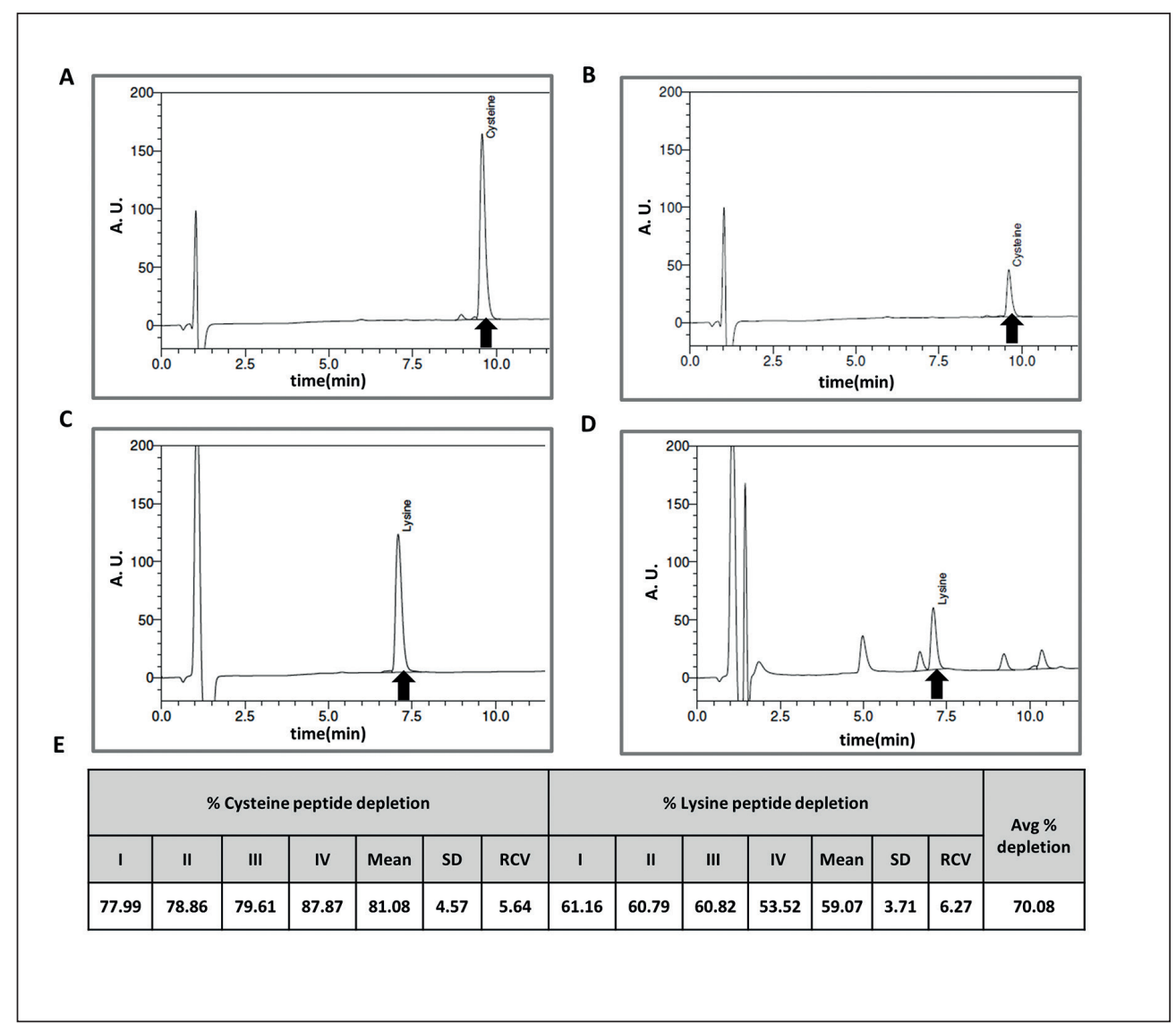

Fig. 1: \% peptide depletion for DPRA positive control A-D) Levels of Cys-peptide in $0.667 \mathrm{mM}, \mathrm{pH} 7.5$ phosphate buffer (A) or Lys-peptide in 0.667 mM, pH 10.2 ammonium acetate buffer (C) (Reference Control B) and Cys-peptide with cinnamaldehyde (B) or Lys-peptide with cinnamaldehyde (D) were analyzed by HPLC-UV, after incubation at $25 \pm 2.5^{\circ} \mathrm{C}$ for $24 \pm 2 \mathrm{~h}$. Retention time for Cys-peptide was $9.4 \mathrm{~min}$ and for Lys-peptide $6.7 \mathrm{~min}$, as indicated by arrows and observed peaks in the representative chromatograms. E) Individual \% depletion values for Cys- and Lyspeptide for four independent replicates and average (Avg) \% depletion as well as standard deviation (SD) were calculated and are indicated in the table.

Mean \% peptide depletion values of four replicates and average (Cys + Lys) \% peptide depletion are presented in Figure $1 \mathrm{E}$. Note that the $\%$ peptide depletion values are within the expected ranges of 60.8 to 100 for Cys-peptide, and 40.2 to 69 for Lys peptide. The RCV for replicates of reference control B that contain only peptides with acetonitrile (solvent) were $0.76,1.04$, $0.89,3.21$ for the Cys-peptide and 0.37, 1.39, 0.94, and 1.67 for the Lys-peptide. For the positive control cinnamaldehyde, RCV values of the \% depletion for Cys- and Lys-peptides were $<14.9$ and $<11.6$, respectively (Fig. 1E). These values are within acceptable ranges as described in OECD TG 442C.

\subsection{Validation of the DPRA assay using OECD TG 442C proficiency chemicals}

Next, we performed the DPRA for 10 proficiency compounds described in OECD TG 442C (Tab. 2). Compounds were incubated with either Cys- or Lys-peptide for $24 \mathrm{~h}$ at $25^{\circ} \mathrm{C}$, followed by detection using HPLC-UV after $24 \mathrm{~h}$ incubation. Retention times for Cys- and Lys-peptides were $9.4 \mathrm{~min}$ and $6.7 \mathrm{~min}$, respectively. A co-elution control was used to check overlapping elution of peptide with compound, if any. The ratio of peptide to test chemical was maintained at 1/10 for Cys- and 1/50 for Lys-peptide. Reference controls containing peptide with solvent (acetonitrile) at $0 \mathrm{~h}$ (reference control $\mathrm{A}$ ) and after $24 \mathrm{~h}$ incubation (reference control B) were made at the same time, followed by immediate analysis of reference control A, whereas reference control B samples were analyzed after the indicated incubation periods at $25 \pm 2.5^{\circ} \mathrm{C}\left(\mathrm{Tab} . \mathrm{S3}^{1}\right)$. Analysis of the co-elution control containing only test chemicals revealed that none of the 10 proficiency chemicals co-eluted with model peptides, as indicated by distinct retention times (Tab. $\mathrm{S} 4^{1}$ ).

Percent depletion values for Cys- and Lys- peptides were determined by comparing the AUC of sample and reference control $\mathrm{B}$ according to Formula 1. Respective values with a corresponding SD for each compound are shown in Figure 1E. Note that SD values are below $14.9 \%$ and $11.6 \%$ for Cys- and Lys-peptides, respectively, for all tested compounds, indicating fulfilment of acceptance criteria. Observed peptide depletion values for each compound are within the expected ranges, except for the $\%$ Cys-peptide depletion value of 66.25 of formaldehyde, which is higher than the expected range of 30-60. Average \% depletion values for both peptides were calculated and used to classify test substances according to the prediction model in Table $\mathrm{S}^{1}$. In accordance with OECD TG 442C, of the 10 proficiency substances, six sensitizers were predicted correctly with average $\%$ depletion values in the range of $18 \%-66 \%$, whereas $\%$ depletion values for 4 compounds below the $6.38 \%$ cut off also correctly predicted them to be non-sensitizers. 
Tab 2: Analysis of DPRA proficiency chemicals

Ten proficiency chemicals described in OECD TG $422 \mathrm{C}$ were incubated with model Cys- or Lys-peptides at $25 \pm 2.5^{\circ} \mathrm{C}$ and levels of each peptide after $24 \pm 2 \mathrm{~h}$ incubation were analysed by HPLC-UV. \% depletion of each peptide caused by the respective chemical was calculated using Formula 1. Values represent the mean of four independent experiments with three replicates in each experiment. Avg $\%$ peptide depletion (Cys + Lys) values were used to classify test substances according to the prediction model in Tab. S51. Note that predictions matched with expected results, as described in OECD TG 442C. "Actual" indicates observed depletion values whereas "Exp" represents expected range of \% depletion values as per OECD TG 442C. SD, standard deviation; S, sensitizer; NS, non-sensitizer; DNCB, 2,4-dinitrochlorobenzene

\begin{tabular}{|c|c|c|c|c|c|c|c|c|c|c|c|}
\hline \multirow[t]{2}{*}{ Sr. No. } & \multirow[t]{2}{*}{ Test chemical } & \multicolumn{3}{|c|}{$\%$ Cys-peptide depletion } & \multicolumn{3}{|c|}{ \% Lys-peptide depletion } & \multicolumn{2}{|c|}{ Avg $\%$ depletion } & \multicolumn{2}{|c|}{ Prediction } \\
\hline & & Actual & SD & Exp & Actual & SD & $\operatorname{Exp}$ & Actual & SD & Actual & Exp \\
\hline 1 & DNCB & 100.00 & 0.00 & $90-100$ & 30.02 & 1.01 & $15-45$ & 65.01 & 0.51 & $\mathrm{~S}$ & $\mathrm{~S}$ \\
\hline 2 & Oxazolone & 73.69 & 1.13 & $60-80$ & 52.03 & 0.84 & $10-55$ & 62.86 & 0.34 & $\mathrm{~S}$ & $\mathrm{~S}$ \\
\hline 3 & Formaldehyde & 66.23 & 0.54 & $30-60$ & 7.07 & 0.69 & $0-24$ & 36.65 & 0.36 & S & $\mathrm{S}$ \\
\hline 4 & Benzylideneacetone & 93.04 & 0.08 & $80-100$ & 1.20 & 0.23 & $0-7$ & 47.12 & 0.14 & S & S \\
\hline 5 & Farnesal & 31.50 & 1.15 & $15-55$ & 5.30 & 0.56 & $0-25$ & 18.40 & 0.71 & $S$ & $\mathrm{~S}$ \\
\hline 6 & 2-3 Butanedione & 64.12 & 0.58 & $60-100$ & 20.33 & 1.79 & $10-45$ & 42.23 & 1.10 & $S$ & S \\
\hline 7 & 1-Butanol & 1.99 & 0.38 & $0-7$ & 0.50 & 0.15 & $0-5.5$ & 1.24 & 0.23 & NS & NS \\
\hline 8 & 6-Methylcoumarin & 2.11 & 0.50 & $0-7$ & 0.00 & 0.54 & $0-5.5$ & 1.05 & 0.25 & NS & NS \\
\hline 9 & Lactic acid & 1.73 & 1.56 & $0-7$ & 0.13 & 0.59 & $0-5.5$ & 0.94 & 0.82 & NS & NS \\
\hline 10 & $\begin{array}{l}\text { 4-Methoxy } \\
\text { acetophenone }\end{array}$ & 1.42 & 1.32 & $0-7$ & 0.30 & 2.13 & $0-5.5$ & 0.87 & 0.76 & NS & NS \\
\hline
\end{tabular}

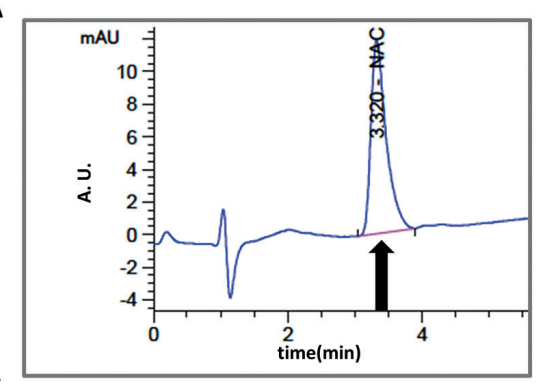

C

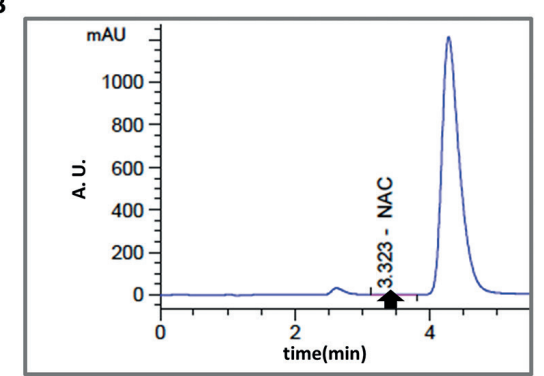

D

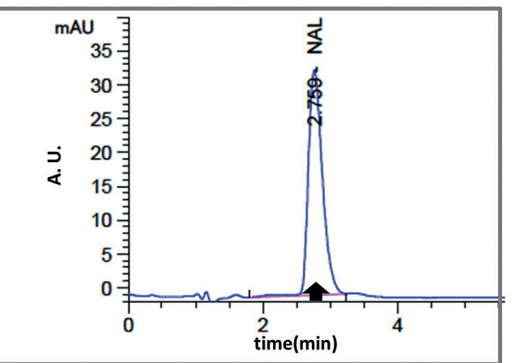

E

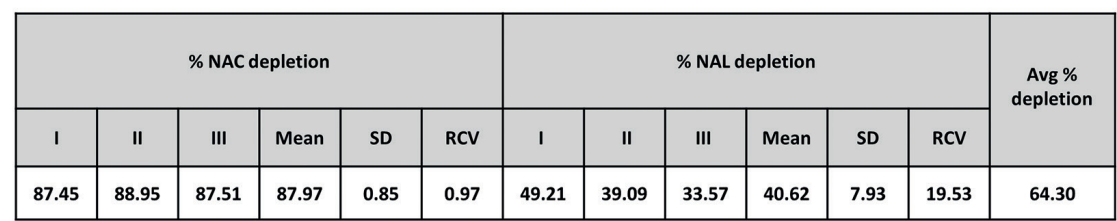

Fig. 2: \% NAC and NAL depletion for cinnamaldehyde

A-D) $1.25 \mathrm{mM}$ each of NAC and NAL in $\mathrm{pH} 9.5$ and $\mathrm{pH} 12.5$ phosphate buffer, respectively, were incubated with $(B, D)$ or without cinnamaldehyde $(A, C)$ for $24 \pm 2 h$ at $25 \pm$ $2.5^{\circ} \mathrm{C}$, followed by detection and analysis using HPLC-UV. Retention time for NAC is $3.3 \mathrm{~min}$ and for NAL is $2.8 \mathrm{~min}$, as indicated by arrows in the representative chromatograms. E) Individual \% depletion values for NAC and NAL peptide for three independent replicates (I-III) and average (Avg) \% depletion as well as standard deviation (SD) were calculated and are shown in the table. 


\subsection{Determination of sensitization potential for 10 proficiency compounds using the ADRA assay}

ADRA was first described by Fujita and co-workers (2014). It makes use of novel cysteine (NAC) and lysine (NAL) derivatives containing a naphthalene ring attached to an $\alpha$-amino group. NAC and NAL were freshly prepared before each experiment and their separation as well as detection methods were established using HPLC-UV. The calibration curves for NAC and NAL showed linear correlations between the dose and UV absorption at $281 \mathrm{~nm}$ with $\mathrm{r}^{2} \geq 0.99$ (Fig. S6C,D ${ }^{1}$ ). Next, we performed ADRA with the DPRA proficiency compounds using NAC and NAL.
Cinnamaldehyde was included as a positive control (Fig. 2). The average \% NAC and NAL depletion value was $64.3 \%$, which is close to the DPRA value. Reference control B (with solvent acetonitrile) and reference control $\mathrm{C}$ (with solvent water) concentrations at $24 \mathrm{~h}$ were calculated and used to determine $\%$ NAC and $\%$ NAL depletion during $24 \mathrm{~h}$. A comparison of $\%$ NAC and NAL depletion values with the values reported by Fujita et al. is shown in Table 3. In addition to the 10 proficiency chemicals (Tab. 3, No. 2-11), we also included 10 chemical substances described by Fujita et al. (2014) (Tab. 3, No. 12-21) and 5 other compounds (Tab. 3, No. 21-26). Reference controls, using respective sol-

Tab 3: \% NAC and NAL depletion in ADRA

Chemicals were incubated with NAC or NAL for $24 \pm 2 \mathrm{~h}$ at $25 \pm 2.5^{\circ} \mathrm{C}$, followed by analysis of NAC and NAL levels using HPLC-UV. \% NAC and NAL depletion values were calculated as described in the methods section. Values represent mean of three independent experiments with three replicates in each experiment. Obtained \% NAC and NAL depletion values (Actual) were compared with average \% NAC and NAL depletion reported by Fujita et al.(2014). SD, standard deviation; N.A., not available

\begin{tabular}{|c|c|c|c|c|c|c|c|c|c|}
\hline \multirow[t]{2}{*}{ Sr. No. } & \multirow[t]{2}{*}{ Test Chemical } & \multicolumn{4}{|c|}{$\%$ NAC depletion } & \multicolumn{4}{|c|}{$\%$ NAL depletion } \\
\hline & & Actual & SD & Fujita et al. & SD & Actual & SD & Fujita et al. & SD \\
\hline 1 & Cinnamaldehyde & 87.97 & 0.85 & 95.5 & 1.6 & 40.62 & 7.93 & 81.3 & 1.8 \\
\hline 2 & DNCB & 100.00 & 0.00 & 100.0 & 0.0 & 77.68 & 3.29 & 83.2 & 0.9 \\
\hline 3 & Oxazolone & 63.61 & 0.51 & 76.5 & 0.4 & 0.00 & 1.09 & 30.1 & 1.8 \\
\hline 4 & Farnesal & 75.67 & 3.00 & 41.3 & 0.8 & 36.41 & 1.64 & 38.6 & 1.9 \\
\hline 5 & Formaldehyde & 83.90 & 0.96 & 81.7 & 1.9 & 50.24 & 2.77 & 65.6 & 2.4 \\
\hline 6 & Benzylideneacetone & 95.11 & 0.12 & 95.3 & 2.1 & 2.87 & 1.69 & 15.0 & 1.1 \\
\hline 7 & 2-3 Butanedione & 100.00 & 0.00 & 100.0 & 0.0 & 72.62 & 3.49 & 73.1 & 2.8 \\
\hline 8 & 1-Butanol & 0.00 & 1.32 & 3.9 & 2.4 & 2.48 & 0.37 & 2.5 & 1.6 \\
\hline 9 & 6-Methylcoumarin & 2.93 & 0.93 & 6.1 & 1.8 & 1.42 & 1.34 & 4.5 & 1.0 \\
\hline 10 & Lactic acid & 0.00 & 0.55 & 0.0 & 1.8 & 2.33 & 0.91 & 2.8 & 1.9 \\
\hline 11 & 4-Methoxyacetophenone & 0.72 & 4.38 & 4.1 & 1.3 & 3.52 & 0.63 & 0.0 & 2.3 \\
\hline 12 & EGDMA & 97.97 & 0.14 & 100.0 & 0.0 & 4.10 & 0.91 & 24.3 & 1.3 \\
\hline 13 & Glycerol & 3.10 & 1.49 & 4.3 & 2.3 & 0.33 & 0.40 & 4.3 & 1.9 \\
\hline 14 & Glutaraldehyde & 100.00 & 0.00 & 49.2 & 0.6 & 42.89 & 1.83 & 96.2 & 1.4 \\
\hline 15 & Imidazolidinyl urea & 66.69 & 1.14 & 80.0 & 0.5 & 73.15 & 1.18 & 83.7 & 1.0 \\
\hline 16 & 2-Mercaptobenzothiazole & 48.70 & 2.48 & 40.0 & 1.9 & 0.00 & 1.41 & 0.0 & 0.8 \\
\hline 17 & Phenylacetaldehyde & 100.00 & 0.00 & 99.8 & 0.4 & 90.42 & 0.74 & 99.2 & 1.0 \\
\hline 18 & Propylene glycol & 0.00 & 1.56 & 0.0 & 2.1 & 0.00 & 0.69 & 0.0 & 1.0 \\
\hline 19 & 2-Propanol & 0.00 & 0.64 & 0.0 & 1.8 & 0.00 & 1.78 & 0.0 & 6.7 \\
\hline 20 & Salicylic acid & 0.00 & 1.65 & 0.0 & 1.4 & 11.36 & 4.41 & 1.5 & 0.7 \\
\hline 21 & Vanillin & 0.00 & 1.69 & 0.0 & 2.3 & 5.09 & 0.57 & 62.7 & 0.6 \\
\hline 22 & Chloramine-T & 100.00 & 0.00 & N. A. & - & 90.97 & 0.91 & N. A. & - \\
\hline 23 & Cinnamyl alcohol & 10.86 & 0.78 & N. A. & - & 1.56 & 0.77 & N. A. & - \\
\hline 24 & Ethanolamine & 8.80 & 3.94 & N. A. & - & 0.08 & 0.98 & N. A. & - \\
\hline 25 & Furaltadone & 85.45 & 1.84 & N. A. & - & 88.98 & 0.87 & N. A. & - \\
\hline 26 & Guaiacol & 8.73 & 3.43 & N. A. & - & 11.04 & 0.78 & N. A. & - \\
\hline
\end{tabular}


Tab 4: Comparison of skin sensitization predictions obtained from DPRA and ADRA analysis

Average Cys + Lys \% peptide depletion and average NAC + NAL \% depletion values obtained in DPRA and ADRA, respectively, for the indicated test chemicals are shown together with respective sensitization predictions. Additionally, average NAC + NAL \% depletion values and respective sensitization predictions reported by Fujita et al. (2014) are shown for comparison of data. ADRA predictions were made as described by Fujita et al. (2014), whereas DPRA predictions were based on OECD TG 442C. EGDMA, ethylene glycol dimethacrylate; DNCB, 2, 4- dinitrochlorobenzene; S, sensitizer; NS, non-sensitizer; Pred, prediction

\begin{tabular}{|c|c|c|c|c|c|c|c|}
\hline \multirow[t]{2}{*}{ Sr. No. } & \multirow[t]{2}{*}{ Test chemical } & \multicolumn{2}{|c|}{ ADRA (Fujita et al., 2014) } & \multicolumn{2}{|l|}{ ADRA } & \multicolumn{2}{|l|}{ DPRA } \\
\hline & & \% Depletion & Pred & \% Depletion & Pred & \% Depletion & Pred \\
\hline 1 & Cinnamaldehyde & 88.4 & S & 64.3 & $S$ & 70.0 & S \\
\hline 2 & DNCB & 91.6 & $S$ & 88.8 & $S$ & 65.0 & $S$ \\
\hline 3 & Oxazolone & 53.3 & $S$ & 31.8 & $S$ & 62.8 & $S$ \\
\hline 4 & Farnesal & 39.9 & $S$ & 56.0 & $S$ & 18.4 & $S$ \\
\hline 5 & Formaldehyde & 73.7 & $\mathrm{~S}$ & 67.0 & $\mathrm{~S}$ & 36.6 & $\mathrm{~S}$ \\
\hline 6 & Benzylideneacetone & 55.1 & $S$ & 48.9 & $S$ & 47.1 & $S$ \\
\hline 7 & 2-3 Butanedione & 86.5 & $S$ & 86.3 & $S$ & 42.2 & $S$ \\
\hline 8 & 1-Butanol & 3.2 & NS & 1.2 & NS & 1.2 & NS \\
\hline 9 & 6-Methylcoumarin & 5.3 & NS & 2.1 & NS & 1.0 & NS \\
\hline 10 & Lactic acid & 0.2 & NS & 1.1 & NS & 0.9 & NS \\
\hline 11 & 4-Methoxyacetophenone & 1.3 & NS & 2.1 & NS & 0.8 & NS \\
\hline 12 & EGDMA & 62.1 & $S$ & 51.0 & $S$ & 73.3 & $S$ \\
\hline 13 & Glutaraldehyde & 72.7 & $S$ & 71.4 & $S$ & 40.4 & $S$ \\
\hline 14 & Glycerol & 4.3 & NS & 1.7 & NS & 4.2 & NS \\
\hline 15 & Imidazolidinyl urea & 81.8 & S & 69.9 & $S$ & 35.2 & $\mathrm{~S}$ \\
\hline 16 & 2-Mercaptobenzothiazole & 19.5 & $S$ & 24.3 & $\mathrm{~S}$ & 32.3 & $\mathrm{~S}$ \\
\hline 17 & Phenylacetaldehyde & 99.5 & $S$ & 95.2 & $S$ & 59.7 & $S$ \\
\hline 18 & Propylene glycol & 0.0 & NS & 0.0 & NS & 2.9 & NS \\
\hline 19 & 2-Propanol & 0.0 & NS & 0.0 & NS & 2.2 & NS \\
\hline 20 & Salicylic acid & 0.0 & NS & 5.6 & NS & 6.8 & NS \\
\hline 21 & Vanillin & 31.3 & $S$ & 2.5 & NS & 4.7 & NS \\
\hline 22 & Chloramine-T & NA & $S$ & 95.4 & $S$ & 100.0 & $\mathrm{~S}$ \\
\hline 23 & Cinnamyl alcohol & NA & NS & 6.2 & NS & 5.5 & NS \\
\hline 24 & Ethanolamine & NA & NS & 4.4 & NS & 4.6 & NS \\
\hline 25 & Furaltadone & NA & $S$ & 87.2 & $S$ & 52.0 & $S$ \\
\hline 26 & Guaiacol & NA & $S$ & 9.8 & $\mathrm{~S}$ & 16.9 & $\mathrm{~S}$ \\
\hline
\end{tabular}

vents, were used for calculating \% depletion. Elution controls were used to determine the retention times of test chemicals; altered mobile phase conditions for the chemicals that co-eluted with NAC or NAL are described in the Methods section.

Individual \% depletion values for certain chemicals such as oxazolone, farnesal, EGDMA, and imidazolidinyl urea varied slightly from the expected value. Also, chemicals such as cinnamaldehyde, glutaraldehyde, formaldehyde, and vanillin contain an aldehyde group, which is particularly sensitive to changes in reaction conditions as it is likely to be oxidized to carboxylic acid. This may contribute to variations in reactivity of aldehydes and hence affect the \% depletion values across the laboratories. Defining the upper and lower limit of $\%$ NAC and \% NAL depletion values for individual chemicals by generating high quality reference data is essential if these values are within acceptable ranges. This can be achieved by careful selection of commercially available ADRA proficiency substances to represent the range of skin sensitization hazard responses. High quality in vivo and 
in vitro reference data generated from EURL-ECVAM-coordinated validation studies has made it easier for laboratories to successfully implement DPRA. A similar approach that enables proficiency testing using reference chemicals will be essential to convincingly establish ADRA as an effective skin sensitization hazard examination tool.

Fujita et al. (2014) described a 2-class prediction model for ADRA depending on the average \% NAC and \% NAL depletion values. Comparison of average $\%$ depletion values showed that out of 21 chemicals that could be compared, the prediction of 20 matched in both studies (Tab. 4). As opposed to Fujita et al. (2014), vanillin was found to be a non-sensitizer in our studies; however, in the same authors' follow up studies with a modified ADRA that employs $1 / 100^{\text {th }}$ concentration of test chemical and shows higher sensitivity and accuracy, vanillin was instead reported to be a non-sensitizer (Yamamoto et al., 2015). We also performed the DPRA assay for these 26 test chemicals and compared ADRA and DPRA results. Our ADRA and DPRA predictions matched for all tested chemicals (Tab. 4).

\subsection{Modification of DPRA to evaluate photo- sensitization of test chemical}

Next, in order to develop an in chemico assay that discriminates photoallergens from non-photoallergens, DPRA was modified to introduce a UV exposure step. Only few chromophores absorb visible light. Of the three UV radiations emitted by the sun, UVA (320-400 nm), UVB (290-320 nm), and UVC (180$290 \mathrm{~nm}$ ), UVA and UVB reach earth's surface, while UVC is blocked by the ozone layer. Exposure tolerance to UVB is limited as even small doses cause sunburn and UVB cannot penetrate the deeper dermis layer (Palmer and White, 2006). UVA is the more abundant radiation in the sunlight and most photo- sensitizers absorb UVA more efficiently than UVB. Therefore, UVA contributes more to phototoxic and photoallergic reactions compared to UVB or visible light. Hence, our studies used UVA radiation to investigate the skin photosensitization hazard of test chemicals.

Test chemicals described in the NRU 3T3 PT test guide were used as reference compounds. The NRU 3T3 PT assay is an OECD (2004) adopted method used to identify the phototoxic potential of test compounds. It relies on assessing the viability of 3T3 fibroblasts exposed to test chemical in the presence and absence of light. Phototoxic compounds such as CPZ, amiodarone, protoporphyrin IX, norfloxacin, and anthracene described in the NRU 3T3 PT test guideline are also known to act as photoallergens (Drucker and Rosen, 2011). Prior to $24 \mathrm{~h}$ incubation, Lys- and Cys-heptapeptides were exposed to $5 \mathrm{~J} / \mathrm{cm}^{2}$ UVA in the presence of test chemical. Reference and elution controls were prepared as described above. The standard curves for Cys- and Lys-peptides were generated as described. Mean \% depletion values of the DPRA positive control cinnamaldehyde for Cys- and Lys-peptides were $82.93 \%$ and $65.86 \%$, respectively, as expected.

Cys- and Lys-peptide \% depletion values with and without UVA irradiation are shown in Table 5. A strong increase in $\%$ peptide depletion upon UVA exposure was seen for CPZ, amiodarone HCL, anthracene and norfloxacin, suggesting their potent photosensitizing nature. This increase in depletion was mostly observed in the Cys-peptide. A moderate increase in $\%$ peptide depletion was observed for protoporphyrin IX. The known photosensitizer hexachlorophene, which does not show phototoxicity in the NRU 3T3 PT assay, also showed a subtle increase in \% depletion upon UVA exposure (Miyachi and Takigawa, 1983). Percent peptide depletion values for sodium

Tab 5: Analysis of photosensitization of NRU 3T3 PT proficiency chemicals by photo-DPRA Indicated test chemicals were exposed to UV in the presence of Cys- or Lys-heptapeptides. Exposure time was adjusted to achieve a dose of $5 \mathrm{~J} / \mathrm{cm}^{2}$ depending upon the measured irradiance. Control non-exposed (- UV) and UV exposed (+ UV) samples were further incubated at $25 \pm 2.5^{\circ} \mathrm{C}$ for $24 \pm 2 \mathrm{~h}$ and peptides were separated and measured by HPLC-UV. \% depletion values of Cys- and Lys-peptide with or without UV exposure were calculated as described in the Methods section. Values represent mean of three independent experiments with three replicates in each experiment. SD, standard deviation; SDS, sodium lauryl sulphate

\begin{tabular}{|l|l|l|l|l|l|l|l|l|l|}
\hline \multirow{2}{*}{ Sr. No. } & \multirow{2}{*}{ Test chemical } & \multicolumn{3}{|l|}{ \% Cys-peptide depletion } & \multicolumn{4}{l|}{ \% Lys-peptide depletion } \\
\cline { 3 - 10 } & & + UV & SD & - UV & SD & + UV & SD & - UV & SD \\
\hline 1 & Cinnamaldehyde & 72.53 & 0.61 & 72.02 & 0.09 & 60.19 & 1.90 & 56.67 & 2.82 \\
\hline 2 & Chlorpromazine & 99.03 & 0.05 & 0.45 & 0.77 & 9.65 & 1.87 & 0.05 & 0.09 \\
\hline 3 & SDS & 1.50 & 1.48 & 0.00 & 0.00 & 94.93 & 0.26 & 95.08 & 0.27 \\
\hline 4 & L-Histidine & 0.00 & 0.00 & 0.00 & 0.00 & 0.28 & 0.49 & 0.34 & 0.59 \\
\hline 5 & Amiodarone HCl & 99.71 & 0.01 & 0.00 & 0.00 & 0.06 & 0.13 & 0.84 & 1.32 \\
\hline 6 & Protoporphyrin IX, disodium & 99.78 & 0.01 & 40.08 & 1.20 & 12.16 & 8.34 & 17.99 & 4.63 \\
\hline 7 & Anthracene & 100.00 & 0.00 & 10.28 & 10.59 & 1.57 & 2.71 & 1.80 & 1.58 \\
\hline 8 & Hexachlorophene & 100.00 & 0.00 & 93.26 & 5.87 & 24.24 & 1.91 & 11.83 & 0.24 \\
\hline 9 & Norfloxacin & 99.18 & 0.06 & 5.64 & 8.23 & 24.14 & 1.25 & 24.18 & 1.13 \\
\hline
\end{tabular}


A

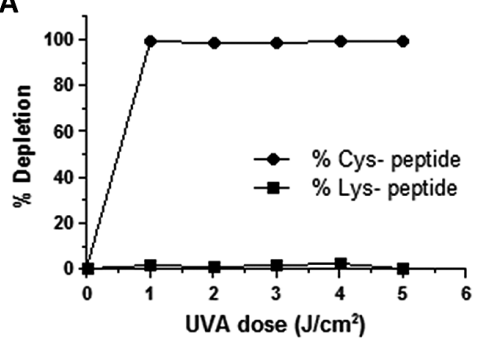

B

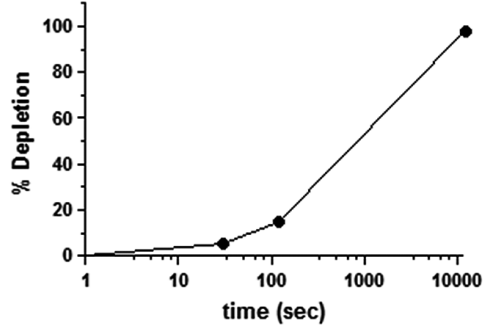

C

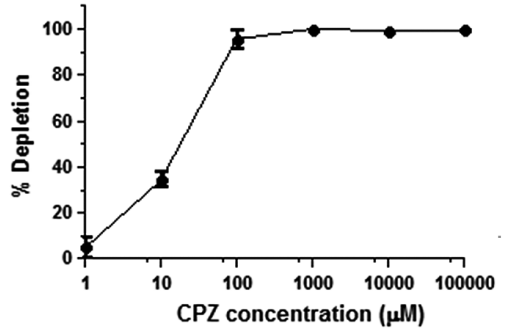

D

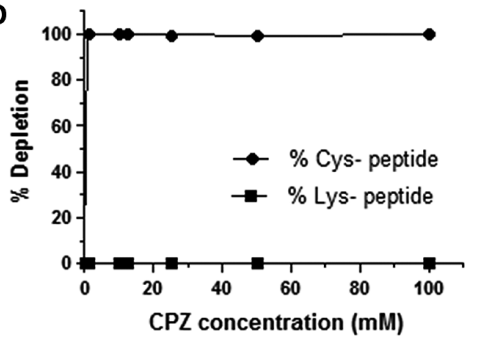

E

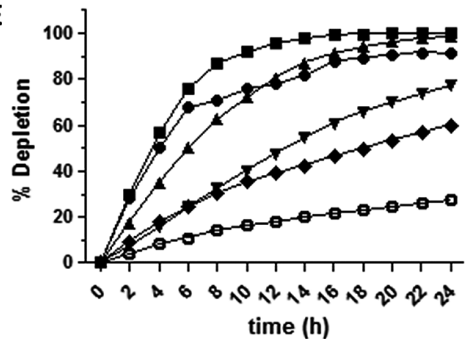
time (h)
Cys-peptide concentration (mM) $\rightarrow 0.21$ $\rightarrow 0.42$ $\rightarrow 0.83$ $\rightarrow \quad 1.67$ $\multimap 3.34$ $\rightarrow 6.67$

Fig. 3: Identification of optimum parameters for photo-DPRA assay

A) CPZ and Cys- or Lys-peptides were exposed to $1 \mathrm{~J} / \mathrm{cm}^{2}$ to $5 \mathrm{~J} / \mathrm{cm}^{2}$ UVA adjusted by exposure time. \% peptide depletion was analyzed by HPLC-UV, after $24 \pm 2 \mathrm{~h}$. B) Cys-peptide and CPZ mixture was exposed to $1 \mathrm{~J} / \mathrm{cm}^{2}$ UVA and was further incubated for the indicated times, followed by HPLC-UV analysis of \% peptide depletion. C, D) Photo-DPRA was performed at the indicated CPZ concentrations using only Cys-peptide (C) or with Cys- and Lys-peptide (D). E) Different concentrations of Cys-peptide were mixed with $100 \mu \mathrm{M}$ (stock concentration) CPZ and incubated for the indicated times after exposure to $5 \mathrm{~J} / \mathrm{cm}^{2}$ UVA. \% peptide depletion was assessed using HPLCUV. Note that the final CPZ concentrations are 20 times lower than the stock concentrations shown here.

lauryl sulfate and L-histidine did not change significantly with or without UV exposure, indicating their non-sensitizing nature in this assay. Note that the DPRA assay is not suited to study sensitization potential of strong detergents like sodium lauryl sulfate (SDS) due to their ionic interactions with the model peptides. This is supported by selective depletion of cationic Lys-peptide in the presence of negatively charged SDS (Tab. 5) and false positive detection of SDS as a sensitizer in DPRA.

\subsection{Optimization of photo-DPRA using chlorpromazine}

To further optimize the photo-DPRA, we used CPZ, which produced the highest \% peptide depletion upon UV exposure and tested the influence of varying assay conditions on \% peptide depletion. We tested whether UVA doses lower than $5 \mathrm{~J} / \mathrm{cm}^{2}$ could photosensitize CPZ. A dose of $1 \mathrm{~J} / \mathrm{cm}^{2}$ was found to be as effective as $5 \mathrm{~J} / \mathrm{cm}^{2}$ (Fig. 3A). Next, we sought the minimum incubation time required to produce the photosensitizing effect of $\mathrm{CPZ}$ after UVA exposure. Incubation for $2 \mathrm{~h}$ was found to induce significant peptide depletion after exposure to $1 \mathrm{~J} / \mathrm{cm}^{2} \mathrm{UVA}$ (Fig. 3B). In previous experiments, $100 \mathrm{mM} \mathrm{CPZ} \mathrm{was} \mathrm{used} \mathrm{to}$ investigate $\%$ peptide depletion. We also tested lower concen- trations and found that as little as $1 \mathrm{mM} \mathrm{CPZ}$ was equally potent (Fig. 3D). Further, an assessment of the impact of CPZ concentrations in the $\mu \mathrm{M}$ range revealed that $90 \%$ of the Cys-peptide was depleted at $100 \mu \mathrm{M} \mathrm{CPZ}$, whereas depletion levels dropped below $40 \%$ at $10 \mu \mathrm{M} \mathrm{CPZ}$ and were below $10 \%$ at $1 \mu \mathrm{M} \mathrm{CPZ}$ (Fig. 3C). Note that the indicated concentrations are those of stock solutions; final concentrations of CPZ were 20 times lower. Next, we also varied the Cys-peptide concentration and monitored its \% depletion at various time points (Fig. 3E). Linear correlations between peptide depletion and incubation time were observed at concentrations of $1.67 \mu \mathrm{M}$ and $3.34 \mu \mathrm{M}$, whereas at lower concentration such linearity was lost after 6-8 h. Very high Cys-peptide concentrations of $6.67 \mu \mathrm{M}$ did not show a linear correlation.

\subsection{Development of photo-ADRA to assess photosensitization potential of test chemicals}

Using a similar approach as that of photo-DPRA, we also developed photo-ADRA to assess the photosensitization potential of test chemicals. The set-up for the assay was similar to photo-DPRA, except that NAC and NAL were used instead of peptides. The standard curves for NAC and NAL are shown in 
Tab 6: Analysis of photosensitization of NRU 3T3 PT proficiency chemicals by photo-ADRA

Indicated test chemicals were exposed to $5 \mathrm{~J} / \mathrm{cm}^{2}$ UVA in the presence of NAC or NAL, followed by further incubation for $24 \pm 2 \mathrm{~h}$ at $25 \pm 2.5^{\circ} \mathrm{C}$. After incubation, non-exposed (- UV) and UV exposed (+ UV) samples were analyzed by HPLC-UV. \% NAC and NAL depletions were calculated as described in the Methods section. Values represent mean of three independent experiments with three replicates in each experiment. SDS, sodium lauryl sulphate; SD, standard deviation

\begin{tabular}{|l|l|l|l|l|l|l|l|l|l|l|}
\hline \multirow{2}{*}{ Sr. No. } & \multirow{2}{*}{ Test chemical } & \multicolumn{4}{|c|}{ \% NAC depletion } & \multicolumn{4}{c|}{ \% NAL depletion } \\
\cline { 3 - 10 } & & + UV & SD & - UV & SD & + UV & SD & - UV & SD \\
\hline 1 & Cinnamaldehyde & 93.41 & 1.59 & 91.64 & 3.96 & 46.58 & 12.57 & 28.80 & 8.06 \\
\hline 2 & Chlorpromazine & 95.50 & 1.45 & 13.79 & 6.46 & 24.34 & 2.54 & 1.18 & 1.37 \\
\hline 3 & SDS & 0.42 & 0.72 & 0.00 & 0.00 & 0.00 & 0.00 & 0.00 & 0.00 \\
\hline 4 & L-Histidine & 0.00 & 0.00 & 0.00 & 0.00 & 0.18 & 0.32 & 0.11 & 0.19 \\
\hline 5 & Amiodarone HCL & 100.00 & 0.00 & 0.00 & 0.00 & 2.10 & 3.38 & 2.83 & 4.45 \\
\hline 6 & Protoporphyrin IX, disodium & 98.01 & 1.06 & 45.37 & 12.30 & 17.95 & 3.88 & 6.90 & 2.42 \\
\hline 7 & Anthracene & 97.94 & 1.78 & 0.00 & 0.00 & 1.22 & 1.22 & 3.42 & 1.73 \\
\hline 8 & Hexachlorophene & 100.00 & 0.00 & 100.00 & 0.00 & 26.15 & 6.49 & 12.28 & 2.98 \\
\hline 9 & Norfloxacin & 100.00 & 0.00 & 2.74 & 2.59 & 1.94 & 1.89 & 1.75 & 1.48 \\
\hline
\end{tabular}

Tab 7: Usefulness of $\triangle U V$ parameter in discrimination of photosensitizing ability of test chemical using photo-DPRA and photo-ADRA

Average \% Cys + Lys-peptide and average \% NAC + NAL depletions, respectively, in photo-DPRA and photo-ADRA were calculated as indicated. Difference in \% depletion values with UV (+ UV) and without UV (- UV) exposure was denoted as $\triangle$ UV. Note the close match between the $\triangle U V$ values of photo-DPRA and photo-ADRA. Avg, average; SDS, sodium lauryl sulphate; SD, standard deviation

\begin{tabular}{|c|c|c|c|c|c|c|c|c|c|c|c|}
\hline \multirow[t]{2}{*}{ Sr. No. } & \multirow[t]{2}{*}{ Test chemical } & \multicolumn{4}{|c|}{ Avg \% depletion DPRA } & \multirow{2}{*}{$\begin{array}{c}\text { DPRA } \\
\Delta U V\end{array}$} & \multicolumn{4}{|c|}{ Avg $\%$ depletion ADRA } & \multirow{2}{*}{$\begin{array}{c}\text { ADRA } \\
\text { DUV }\end{array}$} \\
\hline & & + UV & SD & - UV & SD & & $+U V$ & SD & - UV & SD & \\
\hline 1 & Cinnamaldehyde & 66.36 & 0.65 & 64.35 & 1.44 & 2.01 & 70.00 & 6.16 & 60.22 & 3.74 & 9.78 \\
\hline 2 & Chlorpromazine & 54.34 & 0.92 & 0.25 & 0.43 & 54.09 & 59.92 & 0.98 & 7.48 & 3.91 & 52.44 \\
\hline 3 & SDS & 48.21 & 0.61 & 47.54 & 0.14 & 0.67 & 0.21 & 0.36 & 0.00 & 0.00 & 0.21 \\
\hline 4 & L-Histidine & 0.14 & 0.24 & 0.17 & 0.29 & 0.00 & 0.09 & 0.16 & 0.05 & 0.09 & 0.04 \\
\hline 5 & Amiodarone $\mathrm{HCl}$ & 49.89 & 0.05 & 0.42 & 0.66 & 49.47 & 51.05 & 1.69 & 1.43 & 2.46 & 49.62 \\
\hline 6 & Protoporhyrin IX & 55.97 & 4.17 & 29.04 & 2.86 & 26.93 & 57.98 & 1.79 & 26.14 & 5.78 & 31.84 \\
\hline 7 & Anthracene & 50.78 & 1.36 & 6.04 & 5.79 & 44.74 & 49.58 & 0.46 & 1.71 & 0.86 & 47.87 \\
\hline 8 & Hexachlorophene & 62.12 & 0.95 & 52.54 & 2.82 & 9.58 & 63.08 & 3.25 & 56.14 & 1.49 & 6.94 \\
\hline 9 & Norfloxacin & 61.66 & 0.62 & 15.00 & 4.52 & 46.66 & 50.97 & 0.95 & 2.24 & 1.67 & 48.73 \\
\hline
\end{tabular}

Figure S6C,D ${ }^{1}$. The NAC and NAL \% depletion values with and without UV exposure are shown in Table 6. In agreement with NRU 3T3 PT and photo-DPRA results, CPZ, anthracene, amiodarone $\mathrm{HCl}$, and norfloxacin produced a strong increase in \% depletion upon UV exposure, whereas protoporphyrin IX showed a moderate, and hexachlorophene showed a subtle increase in $\%$ depletion. Histidine and SDS did not show any increase in \% depletion upon UV exposure, as expected.

In order to identify photosensitizers in a robust manner and to distinguish between strong and weak sensitizers with precision, the difference between average $\%$ depletion values in the presence and absence of UV exposure was calculated and defined as $\triangle \mathrm{UV}$ for the photo-DPRA and photo-ADRA assay (Tab. 7). $\Delta \mathrm{UV}$ serves as an indicator of the UV-mediated sensitization potential of a test chemical. In both assays, as expected, $\triangle \mathrm{UV}$ values for strong photosensitizers (CPZ, anthracene, amiodarone $\mathrm{HCl}$, and norfloxacin) were the highest, 44-56, whereas, $\triangle \mathrm{UV}$ for protoporphyrin IX was 26-32 and for hexachlorophene $\Delta U V$ was $6-10$. Note that the $\Delta U V$ values for L-histidine and SDS were below or close to zero in both assays, supporting their 
non-photosensitizing nature. Importantly, $\Delta U V$ values observed in the photo-DPRA and photo-ADRA matched closely for most of the tested compounds. Further screening of test compounds with known photosensitizing abilities will be helpful to define a threshold $\triangle \mathrm{UV}$ value and to categorize photosensitizers.

\section{Discussion}

Multiple alternative methods that include modification of existing tests as well as novel approaches representing different KEs have been proposed and are currently being evaluated to facilitate accurate skin sensitization hazard predictions. The U937 sensitization test (U-SENS ${ }^{\mathrm{TM}}$ ), Interleukin-8 Reporter Gene assay (IL-8 Luc assay), and GARD ${ }^{\mathrm{TM}}$ assay analyze changes in dendritic cell biology similar to h-CLAT, whereas Lu-Sens and SENS-IS assays assess the keratinocyte response much like KeratinoSens $^{\mathrm{TM}}$ (Hoffmann et al., 2018; Roberts, 2018).

Similarly, several in chemico reactivity assays that can be used to assess the MIE in the skin sensitization AOP have been reported in the literature (Aptula et al., 2006; Natsch and Gfeller, 2008; Avonto et al., 2015; Nepal et al., 2018; Zhang et al., 2018). In the present study, we compared and evaluated the utility of two alternative in chemico approaches, DPRA and ADRA, to support the discrimination between skin sensitizers and non-sensitizers as well as photosensitizers. Initially, we used a proficiency system to investigate and compare the technical performance of DPRA and ADRA using the 10 proficiency substances described in OECD TG 442C. According to OECD guidelines, these substances were selected to represent a range of responses for skin sensitization hazard and also because of the availability of high quality reference data. Notably, Cys- and Lys-peptide depletion values for the 10 proficiency compounds fell within the respective reference ranges, except for the Cys-peptide value for formaldehyde. However, this did not affect the prediction outcome, as formaldehyde was predicted to be a sensitizer as expected. As described above in the Results section, inconsistent peptide reactivity with aldehydes is a common phenomenon and may be attributed to oxidation of the aldehyde group of carboxylic acid. Moreover, the test guideline also recommends that 8 out of 10 compound depletion values should fall within the respective reference ranges. Observed values matched with the reference values for 9 proficiency compounds and the predictions were accurate for 10 out of 10 compounds, indicating technical proficiency of the setup.

The DPRA assay is based on HPLC-UV detection of residual Cys- and Lys-peptides, which have relatively low UV absorption. Therefore, it is necessary to use a higher concentration of test chemicals to observe significant depletion of model peptides. This limits the use of highly hydrophobic compounds, especially with the Lys-peptide. To overcome this, LC-MS methods were developed that rely on peptide-chemical adduct detection and use $1 / 25^{\text {th }}$ of the test chemical concentration required for the DPRA (Natsch and Gfeller, 2008; Aleksic et al., 2009). Although more sensitive, LC-MS assays are costly to run and also show poor versatility. A stopped-flow analysis method enables use of a much lower test chemical concentration in the assay; however, analysis performed without separating the test chemicals from the peptides could compromise the detection precision (Chipinda et al., 2010). ADRA makes it possible to use 1/100th of the test chemical concentration required for the DPRA and is also cost-effective as HPLC-UV is used for analysis. Analysis at 281 $\mathrm{nm}$, as opposed to $220 \mathrm{~nm}$, significantly improves the baseline stability of the ADRA (Fujita et al., 2014). Recent studies also suggested that use of EDTA in the ADRA significantly reduces oxidation of the thiol group without affecting prediction accuracy (Fujita et al., 2018).

In light of the described advantages of the ADRA, we carried out a comparative analysis of ADRA and DPRA. The results suggested that both methods predict and discriminate between sensitizers and non-sensitizers equally well. Although we used a limited number of chemicals, the assays had high concordance within their predictions. We suggest that the ADRA and the DPRA could be used as interchangeable methods whenever applicability of one is limited by solubility, precipitation and co-elution of test chemical, or any other technical issue, such as incompatible reaction buffer $\mathrm{pH}$, etc. Both assays provided the same predictions for 25 tested chemicals, which matched previously published data, except for vanillin. Although, vanillin is a known in vivo non-sensitizer, multiple studies reported contradictory in chemico and in vitro data (Basketter et al., 2001; Basketter and Kimber, 2010). This may be due to the reduced reactivity of vanillin's para-hydroxyl benzaldehyde group to form a Schiff base, compared to other aldehydes (Natsch et al., 2012).

Prior to implementation of the 3 Rs principles, tests employing rabbits, guinea pigs, rats, and mice were commonly used to evaluate photoirritation and photoallergy, as well as sensitization. The International Conference on Harmonization (ICH) developed the S10 test guideline for preclinical and clinical photosafety assessment of pharmaceuticals. This guideline is recommended by regulatory bodies in Europe, Japan, Canada, and USA (Food and Drug Administration, HHS, 2015). More recently, non-animal in vitro alternatives such as ITS strategies and the NRU 3T3 PT assay were adopted by regulatory bodies to predict the sensitivity and phototoxicity of test chemicals, respectively (OECD, 2004; Prior et al., 2019). A similar well-defined approach to assess the photosensitizing potential of test chemicals using in vitro methods is not yet available. Here, we show that modification of the DPRA and ADRA by the introduction of a UVA irradiation step is capable of robustly predicting the photosensitizing nature of chemicals. We evaluated test chemicals described in the OECD 432 NRU 3T3 PT assay in photo-DPRA and photo-ADRA. A high correlation between in vivo test outcome and NRU 3T3 PT assay predictions was established (Ceridono et al., 2012). UV-VIS light spectra analysis to check the light absorption pattern as well as measurement of singlet oxygen using ROS (reactive oxygen species) assays has been suggested to evaluate the photosensitive nature of test chemicals (Nishida et al., 2015). However, these are indirect approaches that do not address the MIE or any KE involved in the sensitization AOP. 
Based on the difference in depletion values of a compound in DPRA/ADRA and photo-DPRA/photo-ADRA, we defined a parameter called $\Delta U V$. Higher $\Delta U V$ values denote increased peptide depletion in the presence of UV and thus correlate with a higher photosensitizing ability of a compound. Interestingly, compounds such as $\mathrm{CPZ}$, amiodarone $\mathrm{HCl}$, and anthracene, which are non-sensitizers, were accurately predicted as photosensitizers using photo-DPRA and photo-ADRA, indicating their pre-hapten nature. Further, these assays could potentially discriminate between the photosensitizing potential of strong and moderate photosensitizers such as $\mathrm{CPZ}$ and protoporphyrin IX, respectively. A close match between $\triangle U V$ values in both assays for strong photosensitizers (54.09 v/s 52.44 for CPZ, 49.47 v/s 49.62 for amiodarone $\mathrm{HCl}, 44.74 \mathrm{v} / \mathrm{s} 47.87$ for anthracene and $46.66 \mathrm{v} / \mathrm{s} 48.73$ for norfloxacin) as well as similar predictions of moderate, weak, and non-photosensitizers strongly support the accuracy of the $\Delta \mathrm{UV}$ for identifying photoallergens.

During the course of these studies, another study reporting a similar approach to investigate the photosensitivity of glyphosate-containing pesticides was published by another group (de Ávila et al., 2017). Their data clearly indicated the suitability of photo-DPRA to identify photosensitizers. $\triangle U V$ values calculated from their \% peptide depletion data for protoporphyrin IX and for amiodarone $\mathrm{HCl}$ were 22.16 and 43.57, respectively. Interestingly, these values are close to the $\Delta \mathrm{UV}$ values obtained in our photo-DPRA study. However, a third common test chemical used in both studies, hexachlorophene, did not have concordant $\Delta \mathrm{UV}$ values. Note that \% depletion values for hexachlorophene in our hands showed high experimental variations, which needs further investigation. Independent evaluations of such modified assays using diverse test chemicals belonging to weak, medium, high, or non-photosensitizer categories is critical to promote their acceptance. Moreover, as indicated by photo-DPRA data using CPZ, further optimization of assay conditions, such as UV exposure dose, time, etc. is necessary to use these methods efficiently and in a cost-effective manner.

KEs involved in the photosensitization pathway are essentially the same as those of the sensitization AOP, except that there is an extra triggering event (TE) that involves interaction of light with the test chemical and its excitation to a higher energy level, followed by a common MIE that represents cross-linking of the chemical with protein (haptenization) and subsequent KEs. Thus, in order to evaluate the photosensitivity of a test chemical, adopting a weight-of evidence approach similar to that used to address sensitization, with inclusion of a robust assay to address the TE, would be an ideal approach. The photo-DPRA and photo-ADRA are highly suitable methods to analyze the TE in the photosensitization AOP. An additional advantage of such an approach is the analysis of TE and MIE in the same assay. This will reduce the use of animals in cosmetic/drug testing and will also avoid confusions that are common in the diagnosis of drug induced photosensitization in clinical set-ups (Lugović-Mihić et al., 2017). In vitro test methods that employ UVA exposure of NCTC2544 keratinocytes (Galbiati et al., 2013) and THP-1 monocytes (Hoya et al., 2009; Martínez et al., 2013) to detect IL-18 and IL-8, CD86 and CD54, respectively, and predict keratinocyte/dendritic cell acti- vation and subsequent photosensitization has been described in the literature. This further supports the feasibility of developing an integrated strategy to evaluate photosensitizers.

Overall results show at par performance of ADRA and DPRA in discriminating skin sensitizers from non-sensitizers. Similarly, results also support equal efficiency of photo-DPRA and photo-ADRA in analysis of the photosensitizing potential of test chemicals. Careful repetition and validation of ADRA as well as photo-DPRA and photo-ADRA across laboratories is necessary to underscore their utility. Although only a limited number of chemicals were tested, the pronounced similarity of $\triangle \mathrm{UV}$ values in photo-DPRA and photo-ADRA as well as the effective identification of photosensitizers with these assays is highly promising. Similar to DPRA, validation and adoption of ADRA, photo-DPRA and photo-ADRA by regulatory bodies will be immensely helpful in advancing the use and acceptance of these non-animal alternative methods.

\section{References}

Aleksic, M., Thain, E., Roger, D. et al. (2009). Reactivity profiling: Covalent modification of single nucleophile peptides for skin sensitization risk assessment. Toxicol Sci 108, 401-411. doi:10.1093/toxsci/kfp030

Aptula, A. O., Patlewicz, G., Roberts, D. W. and Schultz, T. W. (2006). Non-enzymatic glutathione reactivity and in vitro toxicity: A non-animal approach to skin sensitization. Toxicol In Vitro 20, 239-247. doi:10.1016/j.tiv.2005.07.003

Avonto, C., Chittiboyina, A. G., Rua, D. and Khan, I. A. (2015). A fluorescence high throughput screening method for the detection of reactive electrophiles as potential skin sensitizers. Toxicol Appl Pharmacol 289, 177-184. doi:10.1016/j.taap.2015.09.027

Basketter, D. A., Wright, Z. M., Warbrick, E. V. et al. (2001). Human potency predictions for aldehydes using the local lymph node assay. Contact Dermatitis 45, 89-94. doi:10.1034/j.16000536.2001.045002089.x

Basketter, D. A. and Kimber, I. (2010). Skin sensitization, false positives and false negatives: Experience with guinea pig assays. J Appl Toxicol 30, 381-386. doi:10.1002/jat.1545

Basketter, D. and Safford, B. (2016). Skin sensitization quantitative risk assessment: A review of underlying assumptions. Regul Toxicol Pharmacol 74, 105-116. doi:10.1016/j.yrtph. 2015.11.013

Ceridono, M., Tellner, P., Bauer, D. et al. (2012). The 3T3 neutral red uptake phototoxicity test: Practical experience and implications for phototoxicity testing - The report of an ECVAM-EFPIA workshop. Regul Toxicol Pharmacol 63, 480488. doi:10.1016/j.yrtph.2012.06.001

Chipinda, I., Ajibola, R. O., Morakinyo, M. K. et al. (2010). Rapid and simple kinetics screening assay for electrophilic dermal sensitizers using nitrobenzenethiol. Chem Res Toxicol 23, 918925. doi:10.1021/tx100003w

Daniel, A. B., Strickland, J., Allen, D. et al. (2018). International regulatory requirements for skin sensitization testing. Regul Toxicol Pharmacol 95, 52-65. doi:10.1016/J.YRTPH.2018. 03.003 
de Ávila, R. I., Teixeira, G. C., Veloso, D. F. M. C. et al. (2017). In vitro assessment of skin sensitization, photosensitization and phototoxicity potential of commercial glyphosate-containing formulations. Toxicol In Vitro 45, 386-392. doi:10.1016/j.tiv. 2017.04.001

Drucker, A. M. and Rosen, C. F. (2011). Drug-induced photosensitivity: culprit drugs, management and prevention. Drug Saf 34, 821-837. doi:10.2165/11592780-00000000000000

EURL ECVAM (2013). EURL ECVAM Recommendation on the Direct Peptide Reactivity Assay (DPRA) for Skin Sensitisation Testing. doi:10.2788/48229

Food and Drug Administration, HHS (2015). International Conference on Harmonisation; S10 photosafety evaluation of pharmaceuticals; guidance for industry; availability. Notice. Fed Regist 80, 4282-4283. http://www.ncbi.nlm.nih.gov/pubmed/ 25730921 (accessed 06.02.2019).

Fujita, M., Yamamoto, Y., Tahara, H. et al. (2014). Development of a prediction method for skin sensitization using novel cysteine and lysine derivatives. J Pharmacol Toxicol Methods 70, 94-105. doi:10.1016/j.vascn.2014.06.001

Fujita, M., Yamamoto, Y., Watanabe, S. et al. (2018). Cause of and countermeasures for oxidation of the cysteine-derived reagent used in the amino acid derivative reactivity assay. $J$ Appl Toxicol 39, 191-208. doi:10.1002/jat.3707

Galbiati, V., Martínez, V., Bianchi, S. et al. (2013). Establishment of an in vitro photoallergy test using NCTC2544 cells and IL18 production. Toxicol In Vitro 27, 103-110. doi:10.1016/j. tiv.2012.09.017

Gerberick, G. F. (2016). The use of peptide reactivity assays for skin sensitisation hazard identification and risk assessment. Altern Lab Anim 44, 437-442. doi:10.1177/026119291604400506

Glatz, M. and Hofbauer, G. F. (2012). Phototoxic and photoallergic cutaneous drug reactions. In L. E. French (ed.), Adverse Cutaneous Drug Eruptions. Chem Immunol Allergy 97, 167-179. doi:10.1159/000335630

Hoffmann, S., Kleinstreuer, N., Alépée, N. et al. (2018). Nonanimal methods to predict skin sensitization (I): The Cosmetics Europe database. Crit Rev Toxicol 48, 344-358. doi:10.1080/10 408444.2018.1429385

Hoya, M., Hirota, M., Suzuki, M. et al. (2009). Development of an in vitro photosensitization assay using human monocytederived cells. Toxicol In Vitro 23, 911-918. doi:10.1016/J.TIV. 2009.03.010

Kimber, I., Basketter, D. A., Berthold, K. et al. (2001). Skin sensitization testing in potency and risk assessment. Toxicol Sci 59, 198-208. doi:10.1093/toxsci/59.2.198

Lugović-Mihić, L., Duvančić, T., Ferček, I. et al. (2017). Druginduced photosensitivity - A continuing diagnostic challenge. Acta Clin Croat 56, 277-283. doi:10.20471/acc.2017.56.02.11

Martínez, V., Galbiati, V., Corsini, E. et al. (2013). Establishment of an in vitro photoassay using THP-1 cells and IL-8 to discriminate photoirritants from photoallergens. Toxicol In Vitro 27, 1920-1927. doi:10.1016/J.TIV.2013.06.013

Miyachi, Y. and Takigawa, M. (1983). Mechanisms of contact photosensitivity in mice. III. Predictive testing of chemicals with photoallergenic potential in mice. Arch Dermatol 119, 736-739. doi:10.1001/archderm.1983.01650330028009

Natsch, A. and Gfeller, H. (2008). LC-MS-based characterization of the peptide reactivity of chemicals to improve the in vitro prediction of the skin sensitization potential. Toxicol Sci 106, 464-478. doi:10.1093/toxsci/kfn194

Natsch, A., Gfeller, H., Haupt, T. and Brunner, G. (2012). Chemical reactivity and skin sensitization potential for benzaldehydes: Can Schiff base formation explain everything? Chem Res Toxicol 25, 2203-2215. doi:10.1021/tx300278t

Nepal, M. R., Shakya, R., Kang, M. J. and Jeong, T. C. (2018). A simple in chemico method for testing skin sensitizing potential of chemicals using small endogenous molecules. Toxicol Lett 289, 75-85. doi:10.1016/j.toxlet.2018.03.006

Nishida, H., Hirota, M., Seto, Y. et al. (2015). Non-animal photosafety screening for complex cosmetic ingredients with photochemical and photobiochemical assessment tools. Regul Toxicol Pharmacol 72, 578-585. doi:10.1016/j.yrtph.2015. 05.029

OECD (2004). Test No. 432: In Vitro 3T3 NRU Phototoxicity Test. OECD Guidelines for the Testing of Chemicals, Section 4. OECD Publishing, Paris. doi:10.1787/9789264071162-en

OECD (2014). The Adverse Outcome Pathway for Skin Sensitisation Initiated by Covalent Binding to Proteins. OECD Series on Testing and Assessment, No. 168. OECD Publishing, Paris. doi:10.1787/9789264221444-en

OECD (2015). Test No. 442C: In Chemico Skin Sensitisation: Direct Peptide Reactivity Assay (DPRA). OECD Guidelines for the Testing of Chemicals, Section 4. OECD Publishing, Paris. doi:10.1787/9789264229709-en

OECD (2018a). Test No. 442D: In Vitro Skin Sensitisation: ARE-Nrf2 Luciferase Test Method. OECD Guidelines for the Testing of Chemicals, Section 4. OECD Publishing, Paris. doi:10.1787/9789264229822-en

OECD (2018b). Test No. 442E: In Vitro Skin Sensitisation. In Vitro Skin Sensitisation assays addressing the Key Event on activation of dendritic cells on the Adverse Outcome Pathway for Skin Sensitisation. OECD Guidelines for the Testing of Chemicals, Section 4. OECD Publishing, Paris. doi:10.1787/9789264264359-en

Palmer, R. A. and White, I. R. (2006). Phototoxic and photoallergic reactions. In P. J. Frosch, T. Menné and J. P. Lepoittevin (eds.), Contact Dermatitis (309-317). Berlin/Heidelberg, Germany: Springer. doi:10.1007/3-540-31301-X_17

Prior, H., Casey, W., Kimber, I. et al. (2019). Reflections on the progress towards non-animal methods for acute toxicity testing of chemicals. Regul Toxicol Pharmacol 102, 30-33. doi:10.1016/j.yrtph.2018.12.008

Roberts, D. W. (2018). Is a combination of assays really needed for non-animal prediction of skin sensitization potential? Performance of the GARD ${ }^{\mathrm{TM}}$ (Genomic Allergen Rapid Detection) assay in comparison with OECD guideline assays alone and in combination. Regul Toxicol Pharmacol 98, 155160. doi:10.1016/j.yrtph.2018.07.014 
Roberts, D. W. and Patlewicz, G. (2018). Non-animal assessment of skin sensitization hazard: Is an integrated testing strategy needed, and if so what should be integrated? J Appl Toxicol 38, 41-50. doi:10.1002/jat.3479

Schultz, T. W., Dimitrova, G., Dimitrov, S. et al. (2016). The adverse outcome pathway for skin sensitisation: Moving closer to replacing animal testing. Altern Lab Anim 44, 453-460. doi:10.1177/026119291604400515

Sewell, F., Gellatly, N., Beaumont, M. et al. (2018). The future trajectory of adverse outcome pathways: A commentary. Arch Toxicol 92, 1657-1661. doi:10.1007/s00204-018-2183-2

Sharma, V. K., Sahni, K. and Wadhwani, A. R. (2013). Photodermatoses in pigmented skin. Photochem Photobiol Sci 12, 65-77. doi:10.1039/c2pp25182e

Silvestre, M. C., Sato, M. N. and Reis, V. M. S. D. (2018). Innate immunity and effector and regulatory mechanisms involved in allergic contact dermatitis. An Bras Dermatol 93, 242-250. doi:10.1590/abd1806-4841.20186340

Strickland, J., Zang, Q., Paris, M. et al. (2017). Multivariate models for prediction of human skin sensitization hazard. $J$ Appl Toxicol 37, 347-360. doi:10.1002/jat.3366

Urbisch, D., Becker, M., Honarvar, N. et al. (2016). Assessment of pre- and pro-haptens using nonanimal test methods for skin sensitization. Chem Res Toxicol 29, 901-913. doi:10.1021/acs. chemrestox.6b00055

Yamamoto, Y., Tahara, H., Usami, R. et al. (2015). A novel in chemico method to detect skin sensitizers in highly diluted reaction conditions. J Appl Toxicol 35, 1348-1360. doi:10.1002/ jat.3139

Zhang, F., Erskine, T., Klapacz, J. et al. (2018). A highly sensitive and selective high pressure liquid chromatography with tandem mass spectrometry (HPLC/MS-MS) method for the direct peptide reactivity assay (DPRA). J Pharmacol Toxicol Methods 94, 1-15. doi:10.1016/J.VASCN.2018.07.004

\section{Conflict of interest}

The authors declare that they have no conflicts of interest. 